Winter 1-12-2017

\title{
Anonymous shell companies: A global audit study and field experiment in 176 countries
}

\author{
Brent B. Allred \\ College of William and Mary, allred@mason.wm.edu \\ Michael G. Findley \\ Daniel Nielson \\ J. C. Sharman
}

Follow this and additional works at: https://scholarworks.wm.edu/aspubs

\section{Recommended Citation}

Allred, Brent B.; Findley, Michael G.; Nielson, Daniel; and Sharman, J. C., Anonymous shell companies: A global audit study and field experiment in 176 countries (2017). JOURNAL OF INTERNATIONAL BUSINESS STUDIES, 49(2).

$10.1057 / \mathrm{s} 41267-017-0135-3$

This Article is brought to you for free and open access by the Arts and Sciences at W\&M ScholarWorks. It has been accepted for inclusion in Arts \& Sciences Articles by an authorized administrator of W\&M ScholarWorks. For more information, please contact scholarworks@wm.edu. 


\section{Anonymous shell companies: A global audit study and field experiment in 176 countries}

\author{
Brent B Allred ${ }^{1}$, \\ Michael G Findley², \\ Daniel Nielson ${ }^{3}$ and \\ J C Sharman ${ }^{4}$
}

${ }^{1}$ Raymond A. Mason School of Business, The College of William \& Mary, Williamsburg, VA, USA; ${ }^{2}$ Department of Government, University of Texas at Austin, Austin, TX, USA; ${ }^{3}$ Department of Political Science, Brigham Young University, Provo, UT, USA; ${ }^{4}$ Department of Politics and International Studies, University of Cambridge, Cambridge, UK

\section{Correspondence:}

BB Allred, Raymond A. Mason School of Business, The College of William \& Mary, Williamsburg, VA, USA

e-mail: allred@mason.wm.edu
Received: 31 August 2015

Revised: 20 July 2016

Accepted: 22 September 2016

Online publication date: 12 January 2017

\begin{abstract}
To test whether firms behave consistently with international law prohibiting anonymous incorporation, we conducted a global audit study and field experiment, using data from 1639 incorporation firms in 176 countries. We requested anonymous incorporation and randomly assigned references to international law, threat of penalties, norms of appropriate behavior, or a placebo. We find a substantial number of firms willing to flout international standards and show that those in OECD countries proved significantly less compliant with rules than in developing countries or tax havens. Firms in tax havens displayed significantly greater compliance and were sensitive to experimental interventions invoking international law.
\end{abstract}

Journal of International Business Studies (2017) 48, 596-619. doi: | 0.1057/s4 | 267-016-0047-7

Keywords: shell corporations; international law; audit study; global field experiment; tax havens

\section{INTRODUCTION}

In the fall of 2014, Russian nuclear executive Vadim Mikerin was decoyed by a fake car alarm into leaving his Washington, DC-area office to be whisked away by US law-enforcement agents. They were attempting to coerce Mikerin to serve as an undercover mole in a probe of suspected kickbacks and bribery involving the sale of Russian uranium in the US (Schectman, 2015). Mikerin was taken to a "war room" equipped with recording devices and radio transmitters and festooned with diagrams of his alleged dealings with Russian nuclear company executives through shell corporations. Mikerin was suspected of participating in schemes to facilitate and hide bribes and kickbacks paid to various officials by sending them through shell companies and secret bank accounts in Latvia, Switzerland, and Cyprus.

While this example may seem as if it were lifted from the plot of a spy novel, the true story underscores that the use of shell corporations often enables illicit and nefarious activities. Although shell companies can serve legitimate legal purposes, they have often been associated with bribery, money laundering, tax evasion, and drug trafficking. ${ }^{1}$ The use of shell companies created headlines in early 2016 when the Panama Papers scandal revealed how extensively they were being employed by heads of state and the wealthy. ${ }^{2}$ Because of these problems, the question arises as to 
whether differences in legal institutions and financial regulation cross-nationally might cause changes in incorporation patterns, which is the first node in corporate governance, and whether those domestic institutions might also condition the effects of international standards on firm behavior.

This moves the focus of concern to global corporate governance, where there is a need to better understand the "conflict, convergence, cooperation and competition among legal systems, institutions, actors and rules" (Wood, Abbott, Black, Eberlein, \& Meidinger, 2015: 334). Global corporate governance adds extra layers of complexity to single-country contexts and has thus required the creation, proliferation, and stabilization of new governance systems transnationally (Djelic \& Quack, 2003). Sugathan \& George (2015) found that the corporate governance effectiveness and the quality of country-level governance infrastructure influence the profit shifting of foreign firms out of host countries. Globerman \& Shapiro (2003) reported that countries that achieve effective governance are more likely to receive foreign direct investment from the United States. Hiller et al. (2011) related evidence that various country-level governance mechanisms significantly affect R\&D investment including strong law enforcement, effective board control, and a bank-based financial system.

Many years ago, Hoskisson, Eden, Lau, \& Wright (2000) identified domestic legal, financial, and political institutions as critical in influencing strategies that transnational businesses adopt. Since then, a consensus has developed among international management scholars that institutions must be considered alongside transaction costs, resources, and corporate governance/agency theory (Kostova, Roth, \& Dacin, 2008; Meyer, Estrin, Bhaumik, \& Peng, 2009; Peng, Wang, \& Jiang, 2008; Wright, Filatotchev, Hoskisson, \& Peng, 2005). Of course, the assertion that institutions matter does not provoke controversy; the key question is how and why they matter, especially across varying national contexts (see Peng et al., 2008).

Individuals and companies must navigate both formal and informal institutions as they do business abroad. Formal institutions include the legal, taxation, and developmental policies of a country (Redding, 2005). Informal institutions are networks and nested organizations influenced by local culture and accepted norms (Leung, Bhagat, Buchan,
Erez, \& Gibson, 2005). Institutions therefore provide the context, or the formal rules and informal norms, that organize and govern individual, nongovernmental organizational, and business interactions (Teegen, Doh, \& Vachani, 2004). Domestic institutions in some countries may encourage or facilitate practices (e.g., anonymous incorporation) that the domestic institutions of other countries may deter or prohibit altogether. Scott (1995: 33) thus describes institutions as the "regulative, normative, and cognitive structures and activities" that create meaning and stability for actions and behaviors. Therefore institutions broadly define society by forming, in the words of Douglas North, "the rules of the game" (Meyer \& Peng, 2005; North, 1990). It is within institutional constraints - both formal and informal - that firms pursue their interests (Ingram \& Silverman, 2002).

However, there is a general consensus in international business studies that too little is known about how institutional contexts differ cross-nationally and how variance in context channels constrains business activities from country to country (Cantwell, Dunning, \& Lundan, 2010; Peng et al., 2008; Redding, 2005). In an attempt to contribute to a better understanding of the variation in institutional contexts globally, in this article we categorize countries into multiple broad types whose formal and informal institutions differently affect how new businesses can be legally incorporated - in ways that carry large implications for firms' compliance with international rules. We do this through an audit study with accompanying field experiment that offers strong causal inference coupled with high naturalism or ecological validity (see Chatterji, Findley, Jensen, Meier, \& Nielson, 2016).

The focus of the study is the creation of shell corporations internationally. Shell companies are legal entities that typically do not produce substantive products or services. ${ }^{3}$ They may be created by private individuals for legitimate purposes, often as holding companies. However, shell corporations may also be used to obscure the real owner of assets or the controlling party behind financial transactions. This kind of company is thus very different from the typical multinational corporation of popular imagination and most international business research. Shell companies are almost always privately held, not publicly listed. ${ }^{4}$ As largely passive holding entities, they are indifferent to profit and loss. Because they produce no substantive good or service, their directors and other officeholders are 
formally exercising legal duties on behalf of the individual owner, not performing any practical management function. They are the first node in corporate governance as limited liability entities, in contrast to the unlimited liability of partnerships or sole proprietorships. As such, incorporation should be a central issue in management research.

The challenge arises when individuals seek untraceable incorporation, particularly internationally, in which the beneficial (real) owner of the shell company cannot be identified. Shell companies whose real owners cannot be discovered may enable a slew of financial crimes. In response to this issue, the Financial Action Task Force (FATF, 2016), an international organization created by the world's leading economic powers, was created to promote and enforce corporate transparency standards worldwide. These standards, now accepted by 180 countries and instantiated in a variety of international conventions and laws, prohibit untraceable shell companies by requiring that governments must be able to "look through" such legal persons to find the real individual or individuals in control, in other words, the beneficial owner.

However, there is a demand for untraceable shell corporations that is in direct tension with the FATF rules. Moreover, the FATF does not audit the intermediary firms - corporate service providers (CSPs) - that create shell companies in member countries to learn if corporate transparency standards are actually being followed in practice. Rather, they assess domestic laws to verify that they harmonize with FATF rules. This gives rise to a potential disconnect between international rules, domestic institutions through informal norms and formal laws, and firm behavior, which is at the heart of this study. Hence the crux of this article is a precise set of tests concerning the effects of information regarding international institutions on incorporation services' conduct, and subgroup tests of how domestic institutions condition or moderate firms' actions in response to information about the global rules. The subgroup tests by country type provide precise measurement of the effects of differences in institutional context on compliance with global rules. The subgroup tests can thus reveal variation in treatment effects induced by the experimental interventions across different categories of country institutional environments.

In this manuscript, we first consider how well international FATF standards have been implemented at the national level with a comparison to incorporation practices as measured in our study. In this, we demonstrate that the grades issued to countries by the FATF in their periodic reviews do not correlate particularly well with the findings on cross-national compliance from our audit study, which is the first global assessment conducted at the firm (corporate service provider) rather than country level. With this discrepancy as background, we then outline theoretical ideas that may provide some explanation for why firms might comply or fail to comply with international standards. These ideas include simply making firms aware of regulations, as expected in a managerial international law approach, as well as highlighting the consequences or appropriateness of certain behaviors.

For the audit study, researchers adopted personas as putative consultants seeking "confidential" incorporation, and 2161 requests were sent to 1639 corporate service providers in 176 countries. A central goal was to uncover global levels of compliance with international standards. In the audit study, we show that levels of compliance are not high, and sometimes troublingly low. Observationally, we find substantial firm-level non-compliance globally, and in investigating the effects within different country groups, we find that firms in tax haven countries were significantly more compliant with transparency standards compared to CSPs in OECD countries and developing nations. This is the study's first evidence that different types of countries evince significantly distinct institutional contexts for incorporation.

As part of the audit study we embedded a field experiment by randomly assigning information regarding FATF standards, including a prompt noting the rules on identification documents, a warning that there might be legal penalties, and an invocation of norms of appropriate behavior. The experimental results indicated few treatment effects for the different international law information conditions across the global sample. However, again providing strong evidence for the importance of institutional context, while CSPs in developed and developing countries proved largely indifferent to the information prompts about standards compared to a neutral placebo, firms in tax havens displayed significantly higher sensitivity to the treatment conditions. This suggests pronounced cross-national heterogeneity in domestic institutions' conditioning effects on firm behavior when potential violations of international standards are encountered. Firms in tax havens responded 
markedly to prompts invoking international law, indicating that the institutional context for incorporation is very different for this type of country compared to wealthy developed and poorer developing nations.

The research design and analysis plan were preregistered with an interdisciplinary research consortium (www.egap.org) prior to the study's execution, and the plan described the inclusion of country type as a blocking criterion. Therefore this subgroup analysis is prescribed as best practice in experimental methods and should alleviate concerns about post hoc "fishing" for significant results. The results offer suggestive evidence that variation across institutional forms captured by country type likely affects firm behavior and moderates the effects of varying information about standards - all dynamics in need of follow-up research. In what follows, we articulate the context for the study, detail the research design, and present our results.

\section{FORMAL LAW VERSUS ACTUAL PRACTICE}

In 1989, the G7 countries established the Financial Action Task Force (hereafter FATF) to combat money laundering by promoting financial transparency, including corporate transparency. This organization developed key recommendations recognized as the standard for battling money laundering and terrorist financing. Aside from the G7, the FATF now includes all members of the G20 and a large majority of the OECD countries. Nearly every other country is a member of regional FATF associate bodies committed to upholding FATF standards. Although the FATF itself only produces soft law, codified in 40 Recommendations, its rules have been explicitly endorsed by the United Nations Security Council, incorporated within World Bank and International Monetary Fund standards, and written into a range of international hard law conventions. Three of these Recommendations have been the most important for improving corporate transparency through identification of the beneficial owner.

The first (\#5), deals with Customer Due Diligence in mandating that banks establish the identity of all account holders, including the identity of the owners of companies that hold corporate accounts. The second (\#12) imposes the same Customer Due Diligence requirements on entities such as casinos, real estate agents, lawyers, and, crucially for our purposes, the corporate service providers that set up and sell shell companies. The third relevant recommendation (\#33), mandates that governments be able to find the real (beneficial) owner of all companies in stating that "countries should ensure that there is adequate, accurate and timely information on the beneficial ownership and control of legal persons that can be obtained or accessed in a timely fashion by competent authorities" (FATF, 2013: 22). ${ }^{5}$

While the problem of untraceable shell companies has attracted renewed attention from the G7, G20, and other bodies in the wake of recent financial crises, efforts have been devoted to better enforcement of the FATF's basic rule on the transparency of companies first laid down in 2003, rather than instituting new standards. As a state rather than federal responsibility, incorporation standards have been largely constant in the US. The EU and Britain introduced important new regulations on corporate transparency in 2015, but the basic goal remains meeting the FATF rule quoted above on identifying beneficial owners.

While it is important for a country to have official laws regarding specific requirements for incorporation, such laws are generally not very useful if they are not followed in practice (see, for example, Allred \& Park, 2007 in regards to formal law versus practice for patent rights). Having laws on the books may help establish legitimacy with the global community, but the lack of enforcement undermines this legitimacy and provides openings to the type of illicit activities that such laws attempt to discourage.

To learn how well domestic laws are enforced in practice, we performed a test of the three key FATF recommendations comparing national-level compliance as assessed by the FATF to the actual firmlevel practice based on our audit study. The FATF conducted Mutual Evaluation Reports (MERs) to determine whether a country is Compliant (C), Largely Compliant (LC), Partially Compliant (PC), or Non-Compliant (NC) with each of the 40 Recommendations. The MERs consisted of a combination of questionnaires, onsite inspections, and plenary discussions of countries' performance.

Appendix B provides a summary of the FATF MER assessments, focusing on the three key FATF recommendations discussed above. FATF MERs were completed for 156 countries for Recommendation 5, with $72(46.2 \%)$ of the countries being NonCompliant, 71 (45.5\%) being Partially Compliant, 13 (8.3\%) being Largely Compliant, and no countries being fully Compliant. For Recommendation 
12, 162 countries have MERs data, with 114 (70.4\%) of the countries being Non-Compliant, 44 (27.2\%) being Partially Compliant, 4 (2.5\%) being Largely Compliant, and no countries being fully Compliant. Recommendation 33 had MER data for 160 countries, with $49(30.6 \%)$ of the countries being Non-Compliant, 85 (53.1\%) being Partially Compliant, 20 (12.5\%) being Largely Compliant, and 6 (3.8\%) being fully Compliant.

While it is helpful to determine the level of compliance at the national level as measured by the FATF's assessment of local laws on the books, the question arises as to whether this translates to actual compliance at the firm level among corporate service providers. Until this study, however, no audit of individual firm behavior existed to compare to the results of national-level assessments. If the two correlate highly, the current FATF protocol may be sufficient. Yet there is good reason to suspect that the alignment of domestic statutory compliance with international standards does not tell the whole story. A central goal of this study, therefore, is to conduct a firm-level audit study of corporate service providers to understand levels of compliance at the crucial locus of behavior, which we can then compare to the MERs report scores. We detail the full design of our audit study below, but for now we point out that national compliance from MER reports does not significantly predict firm-level compliance for FATF Recommendations 5 and 12 (see Appendix C). In fact, it predicts virtually none of the variance. For Recommendation 33 on beneficial ownership, national compliance is a significant predictor (at the $\mathrm{p}<0.05$ level) of CSP compliance, but less than $4 \%$ of the variance is explained, offering weak substantive support for the proposition that statutory law drives firm-level behavior across the full sample. The disconnect underscores the importance of the firm-level audit study, and it also raises questions about why variation in firm-level compliance may occur. We thus turn to a discussion of some possible explanations.

\section{INSTITUTIONAL CONTEXT: CONSEQUENCES VERSUS APPROPRIATENESS}

The lack of strong support above raises questions regarding why some nations may commit to international standards but then fail to enforce them, while others fulfill their commitments at significant cost. Key parts of the answers lead to a reengagement with the discussion of institutional context previewed above. While behavior in international business is likely driven in large part by firm capabilities (Barney, 1991; Wernerfelt, 1984) and industry conditions (Porter, 1980), it is the various countries' institutional contexts that delimit both the informal and formal constraints on managerial actions (Peng et al., 2008) and define legitimate business behavior (North, 1990). Cantwell et al. (2010) posit that economic growth is dependent on the establishment of more advanced institutions. This requires more effective policies and regulations. For example, Demirguc-Kunt et al. (2006) found that incorporated businesses reported fewer obstacles to growth and operations in countries with developed institutions. Although governmental efficiency focuses on the effective implementation of public policy (Galang, 2012), different institutional factors may influence whether and how domestic firms adhere to such policy.

The international business literature has often focused on two broad types of cross-national institutional contexts: developed and developing/ emerging (Cantwell et al., 2010; Meyer \& Sinani, 2009; Wang, Hong, Kafouros, \& Wright, 2012). Developed contexts demonstrate reliable rule of law, efficient regulatory frameworks, and high transparency/low corruption; developing/emerging institutional contexts evince the opposite conditions (Meyer \& Sinani, 2009). This is a useful typology but, as our research details below, it omits an important category of jurisdictions that matter a great deal for international business and finance but cannot be captured by the dichotomous categorization of developed versus developing. The missing type is tax havens, countries that span a range of socio-economic development levels from middle- to upper-income but that also display a distinctive set of legal institutions and norms relevant to incorporation and international business more generally.

Both formal and informal institutions characterize all three types of country contexts, but precise measurement of the effects of formal rules versus informal norms is difficult given traditional methods relying on observational data and is therefore subject to selection bias and collinearity, among other problems. We thus consider different experimental probes drawn from arguments relating to the two broad types of institutions.

Formal institutions generally connect to March and Olsen's (1998) logic of consequences and informal institutions relate to their logic of 
appropriateness. The logic of consequences (hereafter consequences) posits that adherence to laws and standards occur mainly to avoid penalties or to achieve some benefit (March \& Olsen, 1998); actions are therefore based on the anticipated outcomes among alternatives. Consequences applied internationally holds that actors only obey international laws and standards to avoid sanctions or capture gains as dictated by formal rules (Abbott, Keohane, Moravcsik, Slaughter, \& Snidal, 2000; Goldstein, Kahler, Keohane, \& Slaughter, 2000). These formal global rules may be transposed into domestic law and implemented via local government agencies but only have "teeth" when actively enforced. As such, national laws and regulation drive transaction costs (Buckley \& Casson, 1976), so firms should necessarily consider the penalties attached to violations of the formal rules, while also evaluating the risks associated with international political and policy uncertainty (Miller, 1992).

The decision as to whether or not to comply then becomes a classic cost-benefit calculation, encompassing the real and reputational costs and benefits that are expected to come about from specific actions (Checkel, 2001; Drezner, 2007). If the likelihood of being caught or punished is low, or the ultimate cost from subsequent punishments is small, there is limited incentive for a country or firm to follow international law. When penalties are minor or extensive delays in due process occur or can be created, nations may take a 'shoot first and ask for forgiveness later' approach. This tactic implies that when there are limited costs to doing so, countries may publicly promise to abide by international rules but then ignore these commitments to pursue critical economic or security concerns (Goldsmith \& Posner, 2005).

In contrast to consequences, informal practices characterize the logic of appropriateness (hereafter appropriateness), which proposes that national adoption and adherence to international law is a function of and response to accepted norms (March $\&$ Olsen, 1998). The structure of the international system is a social structure (Arend, 1997) and is fundamentally comprised of and based on international law.

This system is premised on binding, meaningful agreements that are themselves critically grounded on commonly accepted norms and beliefs. It is the social and moral commitment to the ideals these rules and laws are based on, not penalties or benefits, which leads countries to adopt and adhere to common standards.

Rather than being the product of cost-benefit calculations, compliance reflects shared norms of proper conduct, internalized through socialization within a community and bolstered through social approbation or disapproval. Trust and reciprocity reduce risk and uncertainty because codes of conduct are institutionalized (Singh, Lentz, \& Nijssen, 2011; Stephan \& Uhlaner, 2010). The emphasis on social mechanisms to ensure compliance (Granovetter, 1985) means that when commitments are not met, punishments take on a more social nature, such as exclusion from marks of prestige, ostracism, or expulsion from a group (Thompson, 1996). Checkel (2001) posits that it is through social learning and persuasion that norms are established and understood and compliance is achieved. Social conditioning helps create structures that stabilize the control and coordination between entities involved in economic exchange (Redding, 2005). Interestingly, Coffee (2001) suggests that norms may matter the most when laws are the weakest.

In the absence of highlighting either the consequences or appropriateness of legal behavior, it is expected that a basic knowledge of the law should prompt compliant behavior. The managerial school of international law (Chayes \& Chayes, 1996), hereafter managerial law, maintains that most countries follow most international rules most of the time. This is because governments conclude that such rules advance their interests for bureaucratic domestic reasons as a compliance machinery is built up, and because of a general sense of obligation to fulfill commitments in the international community. Conversely, non-compliance is ascribed to actors being ignorant of the applicable rules, often because the rules themselves are vague or under-specified.

By shifting the attention to firms (CSPs), rather than countries in aggregate, we have the opportunity to better understand what influences actual compliance with international law. In addition to managerial law, the two opposing theoretical perspectives discussed above - consequences and appropriateness - offer contrasting hypotheses for firm behavior. According to consequences, sanctions and punishment should have a greater influence on firm compliance with standards. This is contrasted with appropriateness, which proposes that adherence to national, industry, or cultural norms should better explain firm willingness to comply. 
Since our earlier test shows that the relationship between national law and compliance at the firm level is marginal at best, shifting attention to firms allows us to better determine whether these theories, or some other factor, can explain which corporate service providers on average may or may not behave consistently with national and international law.

\section{AUDIT STUDY AND FIELD EXPERIMENT ON COMPLIANCE}

To explore firms' compliance with laws pertaining to incorporation and transparency, we employ a first-of-its-kind audit study with an embedded field experiment, which we conducted between March 2011 and July 2012. One key challenge for studying whether firms comply with laws comes from the sensitive nature of this topic. A naturalistic audit study allows us to overcome this challenge by improving the overall ecological validity. Moreover, by including a randomized experimental component, we can consider possible explanations for compliance and provide stronger causal inferences than would be otherwise possible, especially in probing the effects of informal norms, formal rules, and information about international law. This is particularly relevant in exploring how firms in countries evincing different institutional contexts respond to the same experimental interventions. Using a large sample of 1639 firms drawn from 176 countries further enhances the external validity.

In contrast, a survey approach, in which firms are directly asked whether they comply with the law, has obvious limitations with validity and, likely, reliability. With surveys, the expectation is that firms, or the individuals within them, when specifically asked in such a fashion, would indicate and acknowledge that they adhere to all aspects of the law, even though they may not do so in practice. A lab setting would also not be appropriate, since it would be nearly impossible to empanel a proper pool of respondents or create a setting that would accurately resemble the principle players and circumstances for incorporation of firms across the world. Thus a more natural, field-based audit study is most appropriate for the topic at hand.

In our study, we are able to create a situation that does not simply mimic the behavior under consideration, but actually tests such behavior with the relevant real entities, specifically corporate service providers across the world. This permits us to determine whether these providers comply, particularly when an explicit request is made to violate the rules, and when participants are primed with the knowledge of these standards.

We further include a field experimental component. Field experiments have seen limited use in international business research and related fields and are just beginning to attract heightened interest as a methodology for exploring complex and difficult topics in areas such as development economics (Banerjee \& Duflo, 2009; Duflo, Glennerster, \& Kremer, 2008), organizational economics (Bandiera, Barankay, \& Rasul, 2011), behavioral economics (Harrison \& List, 2004; Levitt \& List, 2009), strategic management (Chatterji et al., 2016), and psychology (Shadish \& Cook, 2009). For this field experiment, we consider the theoretical perspectives discussed above, managerial law, consequences, and appropriateness, in designing interventions to learn whether information, penalties, or accepted norms are key motivators for compliance behavior across different institutional contexts.

This design overcomes many of the concerns for survey and lab experiments because the subjects are not self-selected into the sample and are unaware they are being investigated. This issue is particularly important for research in international law, since most of the studies in this field that have employed survey or lab experiments (Chilton \& Tingley, 2013; Hyde, 2007) have been subject to the above criticisms. What is being tested here is the actual behavior of those involved with the incorporation of firms. The scope of this study also gives it high external validity due to an extensive dataset that draws on firms from 176 countries from all economic regions throughout the world. Such coverage overcomes concerns regarding global generalizability from a small sample, or one that is limited in coverage of countries or geographic regions. Such broad country representation also allows the sample to be grouped into categories of developing countries, tax havens, or OECD countries in a way that enables the exploration of effects in different institutional contexts. Using wellestablished classifications means that the results can be more confidently generalized within and across these categories and do not need to be extrapolated from unmatched samples.

\section{METHODOLOGY}

As noted, we employed a global audit study with an embedded field experiment. Birkinshaw, Bresman, $\&$ Nobel (2010) noted the opportunity, if not need, 
to employ experimental approaches to international business research. They indicate that as of 2010, no field experiment had been reported in $J I B S$, and there have been very few, if any, since. To conduct the audit-based experiment, our researchers employed aliases and posed as international consultants desiring to create a confidential shell corporation in the target country hosting the incorporation service.

The study thus employed deception, an ethically vexed and contentious approach. Under the Belmont Report (United States, 1978) standards, deception can only be justified if the costs are low, the benefits high, subjects experience no harm or pain, and there is no other way to conduct the study. All conditions hold for the present research. On average, subjects spent 5-10 min responding to inquiries, often with canned language used in communication with many other customers, so costs were low. No firm-level data existed before the study and therefore the scientific and policy benefits of obtaining firm-level information arguably justified the small amount of time invested by each of the providers. Because the profit-driven crimes enabled by untraceable shell companies comprise serious policy problems that cause a great deal of harm and human suffering, the social benefits of learning from the results are high. The data were fully anonymized so that no adverse consequences would result to the subjects, and all subjects answered inquiries in line with their normal dayto-day routines. Conversely, surveys or other methods using fully informed consent would likely have produced biased results, suggesting that the research could not have been reliably performed using alternative methods (see Findley, Nielson, \& Sharman, 2015). The study aligns with prominent articles in social science employing similar methods (Bertrand \& Mullainathan, 2004; Butler \& Broockman, 2011).

We collected information on a large pool of incorporation services for our sample, and then conducted an audit study with random assignment of placebo or treatment conditions to determine compliance or lack thereof. For the placebo and treatment conditions (discussed below), varying information concerning international law regarding incorporation and its motivation was randomly assigned across the pool. The primary request across all conditions from our fictitious individual clients, including the placebo, was for the CSP to provide its services to create a new corporate entity that would limit tax and legal liability and maintain confidentiality. A request for limited liability, tax savings, and confidentiality does not violate international standards, only an explicit request to avoid supplying ID documents, or the incorporation service provider's failure to require such documentation, violates these standards. Compliance was determined at two levels. First, did the incorporation firm respond to our email? Those that did not were adjudged as exhibiting soft compliance, though as discussed further below, conceivably non-response could have been the product of inattention or a commercial logic. Second, did the firms that responded require the necessary certified identifying photo documentation consistent with international standards (hard compliance for those that did respond)? Because all of our inquiries, including the placebo, asked what identity documents, if any, were required, the determination of whether providers adhered to identification requirements in line with this query comprised the audit portion of the study.

The experimental component involved randomly assigning three treatments (FATF, consequences, and appropriateness), which were tested against a control (the placebo). A reference to international standards alone appears in the first treatment (FATF), but then to test the influence of formal institutions/consequences and informal norms/appropriateness, we added (not replaced) language to the international standards reference that raised the possibility of consequences or the appropriateness of various norms. These three experimental conditions thus map to the three theories discussed above - managerial law, consequences, and appropriateness - and provided information about international standards, as well as incentives or norms to follow those standards. It is possible that some firms already understood the standards, which would make the treatment something more of a prime rather than a pure information treatment. Following the audit study, we conducted a survey and learned that roughly $70 \%$ of firms were not aware of the global standards, but that more firms in tax havens were aware of these standards than those in non-tax havens (Findley, Nielson, \& Sharman, 2014).

Corporate service providers were categorized as residing in OECD, Tax Haven, or Developing countries according to World Bank and OECD classifications. This design allowed for the testing of whether any of the treatments resulted in significantly different compliance (soft or hard) compared to the placebo, and whether the 
institutional context of the country in which the incorporation firm was based influenced the rate of compliance.

To better create a neutral basis for the national source of the inquiry, all email requests came from wealthy, low-corruption OECD country aliases. For this condition, the consultant claimed to be from one of a set of wealthy countries (Norway, Finland, Sweden, Denmark, the Netherlands, Austria, New Zealand, or Australia), which we dubbed the "Norstralia" countries for ease of reference. The Norstralia countries are among the least corrupt countries ranked on the Transparency International Corruption Perceptions Index (CPI). An alias for each country was created based on the most common male names in that country.

\section{Placebo}

The placebo condition was a basic request for confidential incorporation, without any reference to international laws pertaining to incorporation and transparency. In this treatment, the consultant specifically inquired only about what documentation would be required to form a corporation (see Appendix D for examples of the placebo and treatment emails and Figure 1 for a graphical representation of the Treatment Hypotheses).

\section{FATF (Information on Law)}

To test the regulatory influence of the relevant international standards promulgated by the FATF, the first treatment identified the FATF and pertinent international standards. This treatment specifying the requirement for identity documents was intended to evaluate whether the basic knowledge of the law's existence and requirements influences whether incorporation firms were more likely to comply. This intervention thus tests the effects

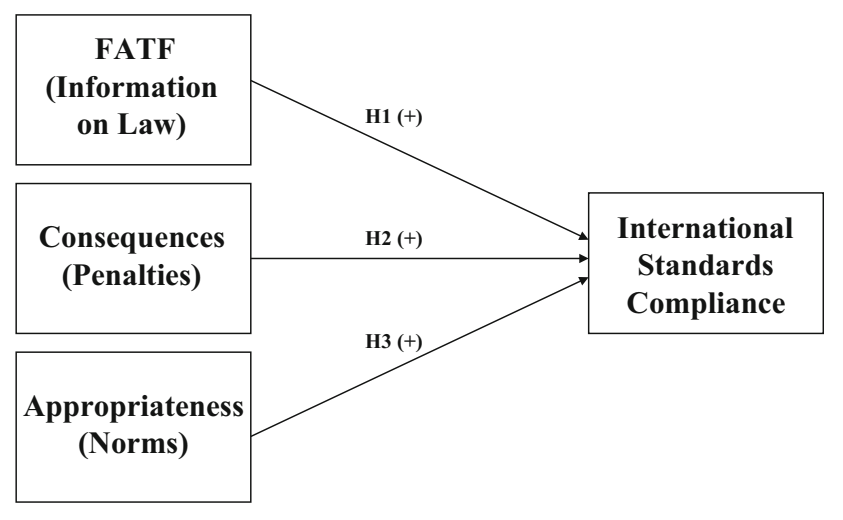

Figure 1 Treatment model. on compliance of information about the formal rules. The consultant indicated that he still desired to limit disclosure and maintain confidentiality and, as with the placebo condition, specifically inquired about the documentation required for incorporation.

As noted, the managerial school of international law (Chayes \& Chayes, 1996) posits that most countries follow international rules through a sense of responsibility to satisfy commitments to the broader international community, and because their interests are best served by so doing. The failure to comply is attributed to lack of knowledge or understanding of relevant rules. This theory leads to the hypothesis that when given information about international standards, incorporation services are more likely to comply with them than when they have not been primed with such information.

Hypothesis 1: Incorporation firms are more likely to comply with international standards when informed of such standards relative to when they are not informed.

\section{Consequences (Formal Penalties)}

The second treatment mentioned international law and raised issues relevant to consequences (Goldstein et al., 2000; March \& Olsen, 1998). As with the International Standards treatment, this treatment provides identical information about FATF and its recommendations for documentation when forming a corporation. To prime the consequences mechanism, this treatment also added that the violation of these standards may result in legal penalties. The consultant then subtly indicated a desire to violate international law by saying that he would prefer to avoid the disclosure of personal information, implying confidentiality and non-compliance with the law. The purpose of this treatment is to determine how incorporation firms react when primed with consequences of violating the formal international standards and law, particularly whether they are more or less likely to comply with the law and risk sanctions. Based upon consequences, the expectation is that the threat and awareness of punishment would increase the rate of compliance with international law, relative to the placebo condition.

Hypothesis 2: Incorporation firms are more likely to comply with international standards when informed of sanctions (consequences) for violating such standards relative to when they are not informed about such sanctions. 


\section{Appropriateness (Informal Norms)}

The third treatment draws upon appropriateness by suggesting that compliance with international law be based on norms of appropriateness and general conformity. This treatment expressly primes the firm by indicating that most countries are signatories with the FATF standards, which require specific disclosure for incorporation. In addition, the treatment emphasizes that "as reputable businessmen" both the applying firm and incorporation firm want "to do the right thing" according to international standards. Even so, the consultant still asks for the ability to incorporate by not disclosing personal information, effectively creating an anonymous corporation and violating the law. The appropriateness approach proposes that in order to conform to generally accepted and shared expectations for suitable behavior, firms will act ethically and appropriately. Thus by providing statements about norms and acceptable practices, higher compliance is expected over both the placebo and international law conditions.

Hypothesis 3: Incorporation firms are more likely to comply with international standards when exposed to norms of appropriateness for adhering to such standards relative to when they are not exposed to these norms.

\section{Host Country Institutional Context}

The scope and breadth of this study's sample allows for further analysis and insight in addition to the three treatments. On top of the treatment effects from the variation in the email message, we are also able to take into consideration host-country characteristics or institutional context, particularly the level of development and nature of the country in which the incorporation service is located and incorporation is being requested. This distinction is particularly valuable since it is not expected that firms across the world behave consistently, as noted above in the discussion of institutional context, but instead that national circumstances may influence the propensity towards compliance to both national laws and international standards. This allows for more nuanced tests of institutional theories of international business. We divided jurisdictions into three categories: OECD, Developing, and Tax Haven countries based on World Bank and OECD classifications. Such categorization reflected the blocking criterion of country type used to sort firms prior to random assignment. We pre-registered this intent before execution of the experiment, and thus the subgroup analysis is justified under norms of best methodological practice.

Prior work had indicated that, contrary to popular perception, firms in tax havens would prove significantly more compliant with international law than firms in developing countries and, surprisingly, also more compliant than firms in developed countries (Sharman, 2010, 2011). Tax havens were originally identified by the OECD as those that host companies are not engaged in substantive business activities, that apply low or zero tax rates, do not exchange tax information with other governments, and have little transparency (OECD, 2009). Tax havens' relatively low power in the global system, combined with the high importance of the incorporation business to their economies, made them especially vulnerable should they appear on the FATF black list. These facts led us to expect quite different behavior from CSPs in tax havens than in developed or developing countries. This prior scholarship suggests three additional hypotheses pertaining to differences across country groups in terms of institutions' conditioning overall compliance and sensitivity to primes regarding international standards (see Figure 2 for a graphical representation of the Host country conditions Hypotheses):

Hypothesis 4: We expect CSPs in tax havens to be more compliant with international standards than firms in OECD (and developing) countries (4A). Tax-haven firms should also be more sensitive when informed of international standards (4B), informed of the consequences for violating these international standards (4C), and when the norms of appropriate behavior to follow international standards are invoked (4D).

Hypothesis 5: We expect CSPs in OECD countries to be less compliant than firms in tax havens (5A). OECD firms should also be less sensitive when informed of international standards (5B), informed of the consequences for violating these international standards (5C), and when the norms of appropriate behavior to follow international standards are invoked (5D).

Hypothesis 6: We expect that CSPs in developing countries will be less compliant than firms in tax havens (6A). Developing country firms should be less sensitive when informed of international standards (6B), informed of the consequences for violating these international standards (6C), and when the norms of appropriate behavior to follow international standards are invoked (6D). 


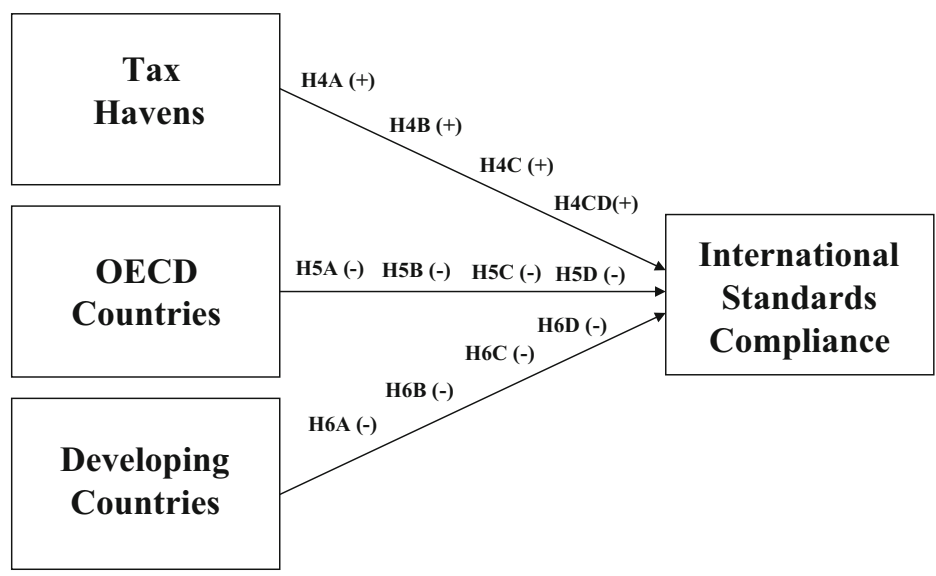

Tax Havens are more compliant than OECD and Developing Countries (H4A/H5A/H6A) Treatment Hypotheses: B = FATF (Information on Law), C = Consequences (Penalties), D = Appropriateness (Norms)

Figure 2 Host country conditions model.

\section{Sample}

To conduct this study, we needed to create a large global pool of firms that incorporate companies for a fee. Information on such firms, particularly at the international level, has not been compiled and does not exist in any central database. As a result, we were required to employ a non-random sampling approach that drew from Internet sources and governmental data. Some CSPs are well-established companies or law firms that specialize in incorporation services, while others provide this function as part of their general offerings. Although we were able to procure data from various commercial listings and governmental sources, our approach drew heavily on Internet searches.

Given the possibility of the existence of reclusive incorporation firms and due to the size of this potential market, it was impossible to obtain information on all CSPs. That said, we are confident we have captured a meaningful percentage of the accessible incorporation firms. Our sample selection process generated firms that have a greater public presence than those that went undetected, whether intentionally or not. Authorities are therefore more likely to scrutinize the firms in our sample, which in turn are expected to have greater compliance than lower-profile incorporation firms. Although this may have resulted in a selection bias towards firms that favor compliance, such a bias would also result in a more conservative test (and under-report noncompliance with international law).

\section{Blocking and Random Assignment}

For the experiment, prior to the random assignment of firms into control and treatment categories, we employed a blocking technique to improve the sample design. Blocking is a procedure that places the sampled firms into naturally or logically similar groupings based on covariate values. As a result, the experimental design allows for results that compare firms with similar characteristics and therefore helps neutralize potential confounds. Block randomization was thus performed within country categories: OECD, Tax Haven, or Developing. We also blocked based on whether the firm was a stand-alone incorporation service or a law firm. Blocking ensures covariate balance across experimental conditions and removes the possibility of high collinearity between covariates (country or firm type) and assignment to the various treatments or placebo (Gerber \& Green, 2012).

We then randomly assigned a Norstralia alias (as mentioned, a putative consultant from Norway, Finland, Sweden, Denmark, the Netherlands, Austria, New Zealand, or Australia) to each email, with an appropriately localized individual name tied to the home country. The text and the subject line were also randomized. The randomization of the subject line was to help mitigate the risk of detection, should two associated firms receive multiple requests. The text of the email represented the placebo or one of the treatment conditions. Unique numbers were assigned to each treatment condition, alias, and email text. We then used the numbers to randomly assign the conditions within each block. Individual treatment texts or subjects lines were not significantly associated with outcomes, and difference-in-means tests indicated that there was good blocking covariate balance 
across experimental conditions. This suggests that the randomization worked as expected.

\section{Implementation}

The study was conducted exclusively through email, with the target firms receiving either the placebo or one of the treatments. In consultation with industry experts, we established that email is the primary mode of communication for CSPs, which had the benefit of allowing us to reach a much larger sample (providers in 176 countries) than we would have with other forms of communication. We wrote and sent the emails exclusively in English because English is the global language of business, individuals from our set of "Norstralia" countries are assumed to be either fluent or very proficient in English, and incorporation services are typically small operations without the capacity to work in a diverse set of different languages. These considerations all default to the global business language of English.

We identified the proper content and tone for the emails to minimize the risk of suggesting that this was a scam letter. Ensuring the plausibility of our email approaches in this manner involved dozens of onsite interviews with CSPs to establish typical client profiles, as well as attending and observing CSP trade conferences in New York, Miami, London, Hong Kong, Singapore, Switzerland, and the Caribbean. To minimize the risk of detection, we drafted 33 separate emails, each of which included a salutation, noted brief background information, signaled the intent for anonymous incorporation, and asked the service which materials were necessary to move forward. These four components were included in all of the emails and any other material in the email text was designed to be purely innocuous. While many experiments hold constant all text except the treatment material, identical language would have substantially raised the risk of detection if firms in the industry forwarded our emails. Within these emails, we then embedded treatment language, which was unique to each treatment, for each of the three conditions specifically noting our awareness of international standards, invoking legal penalties, or raising appropriate behavior (Appendix D provides four examples of emails with specific treatment language highlighted in bold). Thus we used different email bodies and inserted the standard treatment language for each condition, and then in post-estimation tested for letterspecific fixed effects. While a few of the letter texts indicated significant fixed effects (as would be expected by random chance with so many significance tests), controlling for the imbalances did not qualitatively change the effects for the experimental conditions. All emails were sent from a "consultant" indicating a desire to incorporate a firm in pursuit of lower tax obligations, with limited legal liability, and heightened confidentiality. We then coded the replies to our requests to determine levels of compliance.

\section{Coding Protocol}

Full compliance with FATF standards requires that in order to incorporate, certified identity documents, including at least one notarized photo document, be received and verified, and that this documentation be retained so that true ownership can be determined should the need emerge in the future. The lack of such documentation means that the actual owners or those who control the company cannot be identified, which effectively creates an anonymous corporation that can be used for illegitimate purposes.

Email responses were coded as either Compliant, Partially Compliant, or Non-Compliant with international standards, or as Refusal of Service. Responses were deemed Compliant if the incorporation firm required photo identification that was notarized, certified, or apostilled. Partially Compliant firms required photo identification, but did not require it was notarized or certified. Non-Compliant firms did not request any form of photo identity documentation. Incorporation firms that did respond but refused to offer their services were deemed Refusal of Service. Firms from which we did not receive a reply were coded as No Response.

After the incorporation firms responded with the necessary information, the "consultant" replied that their "needs have been met" and that the provider's services would no longer be necessary, effectively terminating the relationship. Although we ended the communication after this correspondence, we are confident that the results would not have changed had we continued through to official incorporation. In an earlier audit study, one of the authors followed up with 45 firms all the way to the final step and even incorporated (in his own name) three of the firms in Nevada, Britain, and the Seychelles (Sharman, 2011). In no case did the service providers respond in one way initially and then change their minds in the end before fully completing the transaction. This impression is strengthened by the extensive interviews with 
CSPs, who explained that it would be commercially counter-productive to send mixed messages to clients as to what documents are required. From these firms' point of view, they want customers to provide all the necessary documentation as soon as possible to complete the transaction quickly, minimizing the time spent completing customer due diligence.

To prevent subjects from determining that the emails actually originated from the US, researchers used proxy servers that assigned random IP addresses. All identifying information regarding the CSPs was removed from emails to ensure their anonymity and prevent harm to subjects. Upon completion of the study, all identifying information was separated from the results and removed so as to fully cover any trail connecting subjects to the results.

\section{ANALYSIS AND RESULTS}

We first consider the overall results of the audit study. In all, 1070 of 2280 emails (or $46.9 \%$ ) did not receive responses. For firms that responded, 203 replies (or 8.9\%) were Non-Compliant, 378 responses (or 16.6\%) were Partially Compliant, 399 replies (or $17.5 \%$ ) were fully Compliant, and 230 responses (or 10.1\%) refused to offer incorporation services. The audit results reveal that noncompliance with international standards is astonishingly high. If one instead calculates the percentage Non-Compliant or Partially Compliant, the results show that $25.5 \%$ of firms were not fully Compliant. When calculated as a percentage of those responding, a full $48 \%$ were not wholly compliant with international standards.

To understand how these results are distributed across different country types and therefore distinct institutional contexts, we computed levels of nonand partial compliance for the three country categories. When restricting the sample to firms in OECD countries only, $27.4 \%$ were not fully compliant and of those responding 51.2\% were not fully compliant. In tax haven countries, $23.6 \%$ were not fully compliant and of those responding $35.5 \%$ were not fully compliant. In developing countries, $24.7 \%$ are not fully compliant and of those responding $55.6 \%$ were not fully compliant. These data show that tax havens have a significantly lower proportion of firms that are out of full compliance with international standards, whereas OECD and developing countries are more similar in compliance levels.
To test our experimental hypotheses using the data from the field experiment, we conducted a comparison of means ( $t$ tests) of the three treatment conditions against the placebo. We then stratified the larger sample into the three country categories (OECD, Tax Haven, and Developing) and completed a similar comparison of means within the country blocks. Although the test of the hypotheses could generally use a one-tailed $t$ test, we took the more conservative approach and use a two-tailed test for all our analyses. See Table 1 for the data and analyses.

While the hypotheses specifically focus on the treatment effects for compliance with the law, they could be expanded to also address the relationship with the other responses. For example, since not replying might be viewed as a form of soft compliance, one might expect a similar relationship with no reply as full compliance. Refusal, while not precisely compliant with the law, indicates an unwillingness to conduct business with a potentially risky customer and has the same end result as compliance: no untraceable shell company is provided. As noted below, although we are unable to conclusively ascertain the reason for not replying, an outright refusal is easier to interpret.

\section{Soft Compliance}

Firms that did not reply to our initial email request or to one of the two follow-up communications, and did not have the email returned undeliverable, could be deemed as having been in soft compliance. Since we do not have any details on the reasons for their not replying, we are unable to conduct more complete analysis of the motives for such soft compliance. However, we did perform a nonresponse check on all firms that failed to reply to any of our repeated inquiries. The inquiries basically asked whether the firm was still in business and assisting international customers and made no mention of taxes, legal liability, or confidentiality. A very small proportion of non-responding firms replied to this inquiry (less than 5\%), suggesting that soft compliance may not in fact account for much of response rate beyond the variance across experimental conditions.

For many of the target firms, we assume that the potentially dubious nature of the solicitation, regardless of the placebo or treatment condition, prompts some firms to simply ignore our request and not provide an explanation for why, leading to soft compliance. Out of the overall sample, 1070 of 2280 requests, or $46.9 \%$, did not respond to our 
Table 1 Displays difference in means tests for the total sample, OECD countries, Tax Haven countries, and Developing countries (row blocks) for the five possible outcomes of no-reply, non-compliant, partial compliant, compliant, and refusal (rows within blocks) for the Placebo, FATF, Consequences, and Appropriateness experimental conditions (columns)

\begin{tabular}{lcc}
\hline Response & Placebo & FAFT (information on law) \\
& & \\
\hline Comparison of means between placebo and treatments - total sample \\
No reply & $44.75 \%$ & $49.46 \%$ \\
Non-compliant & $8.42 \%$ & $8.11 \%$ \\
Partial compliant & $16.65 \%$ & $16.22 \%$ \\
Compliant & $19.49 \%$ & $16.76 \%$ \\
Refusal & $10.69 \%$ & $9.46 \%$ \\
Total & $100.00 \%$ & $100.00 \%$ \\
n & 1057 & 370
\end{tabular}

Comparison of means between placebo and treatments - OECD countries

$\begin{array}{lrr}\text { No reply } & 44.72 \% & 46.81 \% \\ \text { Non-compliant } & 13.73 \% & 14.89 \% \\ \text { Partial compliant } & 15.14 \% & 13.83 \% \\ \text { Compliant } & 14.09 \% & 8.51 \% \\ \text { Refusal } & 12.32 \% & 15.96 \% \\ \text { Total } & 100.00 \% & 100.00 \%\end{array}$

Comparison of means between placebo and treatments - Tax Haven countries

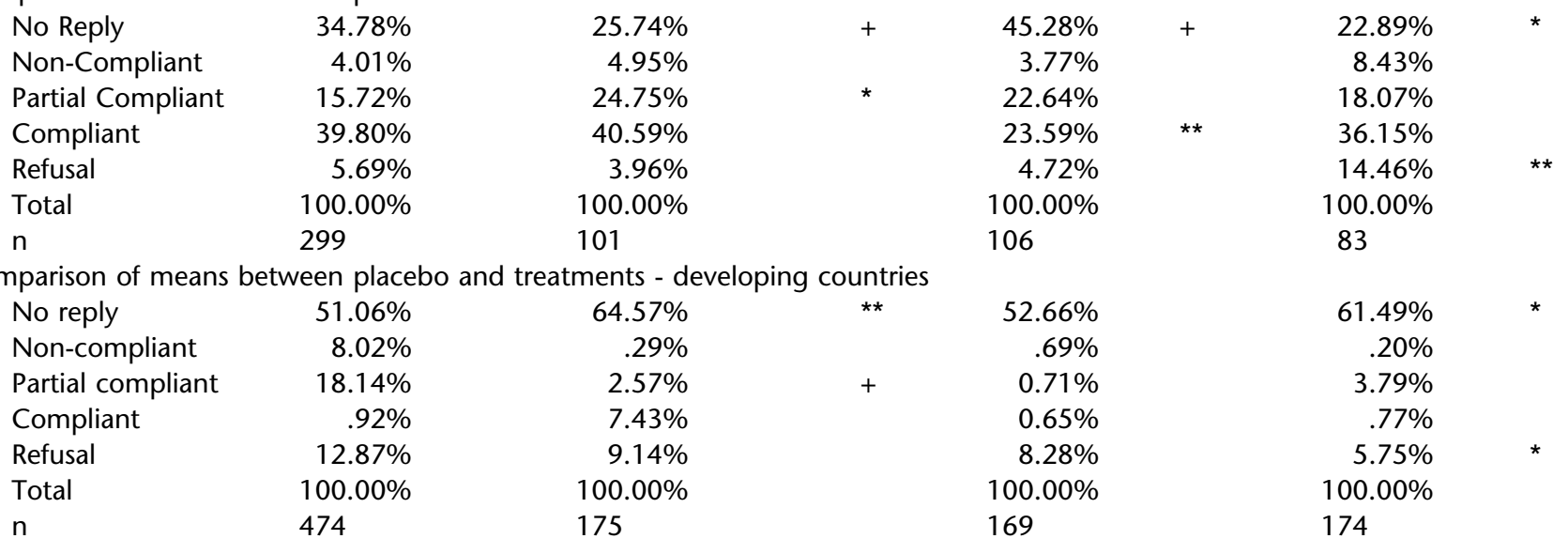

Notes: Each entry refers to the percent of subjects in a country block who received a given condition and responded in a certain way. Those percentages are accompanied by significance tests, which compare the FATF, Consequences, and Appropriateness conditions to the Placebo and identify when they are meaningfully different outcomes.

Sig. significance of difference between mean of Placebo and each treatment.

$+\mathrm{p}<0.10 ;{ }^{*} \mathrm{p}<0.05 ;{ }^{* *} \mathrm{p}<0.01 ;{ }^{* * *} \mathrm{p}<0.001$.

email. For the total sample, there is no significant difference between the three treatments and the placebo for no reply, with all four conditions falling within $2.6 \%$ of the average across all conditions. For the three country conditions, there is greater variance for the placebo no reply condition (44.7, 34.8, and 51.1\% for OECD, Tax Haven, and Developing countries, respectively), and these differences are significant statistically at the $\mathrm{p}<0.05$ level.

Within the country subgroups, for OECD countries, there is no significant difference between the placebo and the three treatments for no reply. For developing countries, the FATF treatment (64.6 versus $51.1 \%, \mathrm{p}<0.01)$ and the appropriateness treatment $(61.5$ versus $51.1 \%, \mathrm{p}<0.05)$ are significantly higher than the placebo for no reply. For Tax Haven countries, we see significant differences in the non-response rate for all three conditions, with the FATF treatment having $10 \%$ less no reply (24.7 versus $34.8 \%, \mathrm{p}<0.10$ ), the consequences treatment 9.5\% higher $(\mathrm{p}<0.10)$ and appropriateness $11.9 \%$ lower $(\mathrm{p}<0.05)$ than the placebo condition. An interesting take away from these findings shows that in Tax Havens significantly more firms reply (the opposite outcome from no reply) when informed of international law or norms and less 
when informed of penalties than the placebo condition.

\section{FATF (Information on Law) Treatment (Hypothesis 1)}

For the FATF treatment, we primed the incorporation firm with the information that identified FATF and the pertinent international standards on corporate transparency. Hypothesis 1 states that when information about international standards and laws is provided, the CSP is more likely to comply with them than when no information is provided. As seen in Table 1, there are no significant differences between the FATF treatment and the placebo for the full sample of responses, including full compliance, failing to support H1. For this treatment, no reply increases from $44.5 \%$ in the placebo to $49.0 \%$, but compliant drops from $18.9 \%$ to $16.9 \%$ and refusal (a different sort of compliance) also declines from $11.2 \%$ to $9.5 \%$, but none of these changes are significant statistically.

\section{Consequences (Penalties) Treatment (Hypothesis 2)}

For the Consequences treatment, we provided similar details with the FATF treatment, but added information about potential financial penalties that could result from non-compliance. Hypothesis 2 predicts higher compliance will result when consequences for violation to international standards are raised. Only refusal had a significant change (a decrease to $7.6 \%, \mathrm{p}<0.05$ ), but this is in the opposite direction as expected, failing to support this hypothesis (H2). As with the International Law treatment, no reply increases (to 49.2\%) and Compliant drops (to 16.0\%), but neither are significant changes. These decreases in Compliant and Refusal seem to be offset by the increase in the no reply (soft compliance) and Part Compliant.

\section{Appropriateness (Norms) Treatment (Hypothesis 3)}

For the Appropriateness treatment, we appealed to the target's sense of doing what is right by suggesting that compliance with international law be based on norms of appropriateness and general conformity. The Norms Hypothesis asserts higher compliance when norms of appropriateness are invoked, but as with the other two treatments, we find compliance actually decreases (to $15.5 \%$ ), but insignificantly, failing to support H3. We do find a marginal significantly higher rate for no reply, which increased to $49.5 \% \quad(\mathrm{p}<0.10)$. One explanation may be that "accepted norms" may be not be universally agreed upon, and as with culture, may differ across countries (Leung \& Morris, 2015).

These results provide no support for any of the primary treatment hypotheses and only find a significant relationship for refusal responses under the consequences treatment, but in the opposite direction as expected. Greater insight into why these relationships are not found may be gained by stratifying the total sample into country categories to determine if the nature of the institutional context in the country in which the CSP is based affects behavior differently. As noted above, the field experiment was deliberately designed in the use of block randomization so that we could test if firms in OECD, Tax Haven, and Developing countries responded differently to our treatments.

\section{Tax Haven Countries (Hypothesis 4)}

We hypothesized that CSPs in tax haven countries are less likely to violate international law and have higher compliance than firms in OECD and developing countries (H4A). We also hypothesized that, when informed of international standards (H4B), informed of the consequences for violating these international standards (H4C), and when the norms of appropriate behavior to follow international standards are appealed to (H4D), tax havens would be more sensitive to these prompts priming international law. The overall soft compliance rates (no reply) were significantly lower in tax havens than OECD and Developing countries (33.5 versus 46.6 and $55.5 \%$, respectively). This means that CSPs in tax havens were more likely to respond to our requests than in OECD countries and developing countries. Nearly two-thirds of tax-haven firms responded, in contrast to less than half of developing country firms. It seems like the increased response rate is found in a significantly higher compliance rate $(36.5 \%$ for tax havens versus $13.3 \%$ for OECD countries and $9.6 \%$ for developing countries). Firms in tax havens are nearly three times more likely to be fully compliant than firms in OECD countries and nearly four times more likely than firms in developing countries. Although CSPs in tax havens have lower refusal rates than in OECD and developing countries, this seems a result of much higher compliance rates, supporting H4A.

Within the tax haven countries, we find that for the International Law treatment, the no reply rate is marginally significantly lower $(p<0.10)$ and the partial compliant rate significantly higher $(\mathrm{p}<0.05)$ 
than the placebo condition, but we do not find much of a change in full compliance. In contrast, for the consequences treatment, the no reply rate marginally significantly increases $(\mathrm{p}<0.10)$ and the compliant rate significantly drops $(\mathrm{p}<0.01)$. For the appropriateness treatment, no reply is also significantly lower $(\mathrm{p}<0.05)$ and the refusal rate is significantly higher $(\mathrm{p}<0.01)$. When informed of international law, tax-haven firms respond to our request more often and have increasing partial, but not full compliance. When informed of penalties, hard compliance drops, but this seems to be because of a shift to the soft compliance of not responding to our request. When accepted norms are invoked, more firms respond, but then explicitly refuse to do business with us. Interestingly, while just out of marginal significance $(p<0.11)$, the penalties condition encourages higher partial compliance and the norms condition results in higher non-compliance. These results provide some support for Hypothesis 4 considering CSPs in tax havens, which demonstrated significantly higher compliance with global standards and more sensitivity to prompts about those standards than firms in OECD and developing countries.

\section{OECD Countries (Hypothesis 5)}

Hypothesis 5 predicted that, compared to tax havens, CSPs based in OECD countries would be less likely to comply with international standards (H5A) and would prove less sensitive when informed of international standards (H5B), informed of the consequences for violating these international standards (H5C), and when the norms of appropriate behavior to follow international standards are appealed to (H5D). While there is some variance seen across the treatments when considering response rates, there are no significant differences between the placebo condition and any of the treatments for all five outcome measures, offering only support for Hypothesis 5A.

\section{Developing Countries (Hypothesis 6)}

As discussed above, developing countries face different pressures than OECD and tax-haven countries. While they are pressured to accept the same global norms for laws and transparency, they may neither have the resources to enforce the laws, nor be dissuaded by potential penalties. Thus the Developing Country Hypothesis proposed that, compared to firms in tax havens, incorporation firms in developing countries should be less likely to comply with international standards (H6A) and be less sensitive when informed of international standards (H6B), when notified of the consequences for violating these international standards (H6C), and when the request appeals to norms of appropriate behavior in following international standards (H6D). While we find support for H6A, we find that none of the conditions create a significant change in full compliance over the placebo. We do find that when informed of international law, developing country firms are less likely to even respond, with no reply increasing from 51.1 to $64.6 \%(\mathrm{p}<0.01)$, and are less likely to be partially compliant, decreasing from 18.1 to $12.6 \%(\mathrm{p}<0.10)$. The penalties condition results in no significant changes. The norms condition also exhibited a significant increase in no reply (to $61.5 \%, \mathrm{p}<0.05)$ and a significant drop in refusal from 12.9 to $5.8 \%(\mathrm{p}<0.05)$. Firms in developing countries appear more sensitive to the priming conditions than firms in OECD countries, but the sensitivity we do see appears to cut in opposite directions from firms in tax havens.

The results of these comparison-in-means tests are robust qualitatively to logistic regression analysis, considering each outcome category separately with the other outcomes as the comparison sets. Additionally, although it has not yet become standard practice in social science or business studies, statistical best methods recommend the employment of corrections for multiple comparisons given that significant results at the $\mathrm{p}<0.05$ level should be expected in one of twenty tests based on chance alone. We therefore made use of two methods to adjust for multiple comparisons. We employed the more conservative family-wiseerror-rate adjustment using the Bonferroni method (Dunn, 1961), and we also controlled for the falsediscovery rate with the less draconian BenjaminiHochberg procedure (Benjamini \& Hochberg, 1995). As is common, many of the results did not clear the amended critical $p$-value thresholds for significance, but other key results held. Notably, for the tax haven subgroup, the effects were robust to both multiple testing corrections of the norms treatment in significantly increasing refusal rates and the penalties condition in significantly decreasing the compliance rate (presumably because the firms that would otherwise have proved compliant did not reply). ${ }^{6}$

All told, the subgroup analysis provides support for the importance of institutional context, particularly regarding tax havens. Firms in tax havens were significantly more compliant than firms in 
OECD or developing countries and significantly more sensitive to prompts regarding international law, formal penalties for violating the standards, and informal norms enjoining conformity. These results underscore the need for studies that are sensitive to institutional context but also for more nuanced categorization of countries according to their rule of law and position in the global economy, at least considering tax havens as a distinct category when studying international finance, incorporation, and law.

\section{DISCUSSION AND CONCLUSIONS}

The audit study and accompanying field experiment offer interesting results and important implications for scholars and national policymakers. We first considered overall levels of firms' compliance and found that they neither match well the FATF national level assessments, nor do they offer a particularly optimistic view about financial and legal institutions in global corporate governance. This key finding from the audit study extends beyond our earlier work (Findley et al., 2014), which was almost exclusively experimental and focused on different experimental treatments, specifically ones related to terrorism, corruption, the IRS, and offering a premium. In particular it extends the work to a careful consideration of the importance of institutional context in conditioning compliance with global corporate transparency standards.

As shown by the 2016 Panama Papers scandal and this article, it seems that the efforts the international community is putting into improving corporate transparency are not generally working. It also appears that it is not very difficult to create an anonymous shell corporation. While it is initially encouraging that nearly $75 \%$ of the total sample of incorporation firms either did not reply, proved fully compliant, or refused service, that still leaves roughly $25 \%$ of these firms that do not comply or are only partially compliant. The inference is that, should potential criminals wish to set up an untraceable shell company, all they need to do is shop around and they would succeed, on average, within four attempts.

We then divided the sample to learn whether national characteristics help explain behavior, consistent with institutional arguments in international business. We found compelling evidence for institutional differences across country types. For OECD countries, the lack of significant changes in any responses across the three treatments was unexpected and concerning. These countries' claims to be leading the way in adhering to the global rules they created to counter money laundering and associated crimes does not find evidence in the data. The overall full compliance rate for OECD countries is $13.8 \%$, which is higher than the $9.6 \%$ for developing countries, but is significantly lower than Tax Havens (36.5\%). With $27.4 \%$ of incorporation firms either being non-compliant or only partially compliant, it apparently does not take much effort to set up an anonymous shell corporation in an OECD country.

In contrast, firms in tax havens, where we initially expected greater challenges to setting up an untraceable shell corporation, had actual compliance rates of more than a third, and had the lowest non-compliance rate of any category (4.8 versus $13.1 \%$ for OECD countries and $7.9 \%$ for developing countries). Incorporation firms in Tax Havens are thus found to be more likely to comply with international law for incorporation. One explanation may be that small, vulnerable tax haven countries and firms are responding to the increased scrutiny from the rest of the world by improving corporate governance and transparency (Sharman, 2010, 2011).

For the experimental portion of the study, we hypothesized that CSPs, when given information about international law, potential penalties, and generally accepted norms, would be more likely to comply with the law. We found that this is not the case on the whole. In fact, when primed about international law, penalties, and norms, compliance to the law and refusal to proceed with our request actually decreased, something we did not expect. We did find that in all three treatments, the incorporation firm's soft compliance, as measured by the rate of non-response, did increase, but only with marginal significance for the appropriateness treatment. It seems that these treatments did not significantly increase the likelihood for hard compliance to international laws across all country groups.

However, for the treatment effects in tax havens, the no reply was marginally to highly significant for all three treatments, with a decrease in no reply for the FATF and appropriateness treatments, but an increase for the consequences treatment. For the latter, it appears that the increase in non-response came out of a decrease in compliance. One defensible inference is that otherwise compliant firms in tax havens, when informed of penalties, are 
basically ignoring our requests and not responding. In contrast, when primed with acceptable norms, tax haven firms are more likely to respond, but also more likely to refuse service outright, perhaps in response to the apparent disingenuousness of the appeal to appropriateness.

Although the tax havens provide the most intriguing results and those most consistent with institutional theories of international business, incorporation firms in developing countries also provide some interesting insights. Developing countries had the highest overall no reply rate $(55.5 \%)$, and within this category, the international law and norms treatments had even significantly higher non-response rates over the placebo. Overall compliance rates were low $(9.6 \%)$ in developing countries and the treatments did not significantly improve compliance but rather, in multiple cases, worsened adherence to global standards. This might be explained as resulting from these countries' lack of resources or incentives to enforce international law.

One key implication of our findings is that OECD countries need to do more to get their own houses in order. Our study argues that the low overall rate of compliance and the practical ease of obtaining prohibited shell companies in OECD countries does not call for new laws, but for re-doubled efforts to make these laws effective.

\section{LIMITATIONS AND FUTURE RESEARCH}

Although the use of an audit study with embedded field experiment helps overcome many concerns that might be leveled at other methodologies that might be used to study this phenomenon, such as surveys or lab studies, other limitations for this study should be identified. As noted above, our sample selection relied heavily on Internet searches to compile a subject pool of CSPs around the world, since no database for such firms is available. We recognize that we were unable to document the complete population of CSPs, but are comfortable with the sample we ultimately developed. We were able to create a large sample of firms involved with providing incorporation services with broad coverage in terms of countries and regions. The blocking and randomization process did not favor any type of firm, country, or region, allowing high confidence in and strong generalization from the results. In addition, since the firms we were able to identify are more visible, we believe our sample provides for a more conservative test, since we suspect that firms that may intentionally be difficult to find are more likely to violate international law.

Due to the nature of our field study, we were unable to further explore or better understand the logic for why a firm did not reply. There may have been an element of soft compliance, but a followup round of communication did not offer strong evidence of this. For the tax haven countries, the no reply rate varied significantly, from as low as $22.9 \%$ for appropriateness to as high as $45.3 \%$ for consequences, so we are confident that the treatments did affect the firm's propensity to reply and which response they provided. Such variance for no reply had implications on other responses, and gaining a better grasp for why a firm did not reply would be helpful to further understand the treatment effects in light of selection into response.

We recognize that the client profiles we use in this study are from developed countries, limiting the conclusions we can draw accordingly. This design was intentional to ensure consistency from the incorporating firm perspective. While it is expected that there is a wide variety of potential customers wishing to set up shell companies, in setting up our customer profiles we have aimed to replicate a reasonably typical shell-company buyer. In particular, one interested in limited liability, tax minimization, and confidentiality/secrecy from a developed country. Future research could further explore the implications from having the incorporating entity based in a wider range of countries, including developing countries.

While we adopted the conventional country classifications of OECD, Tax Haven, and Developing countries to segment our sample and test our hypotheses, there are other categories that would also be interesting to consider. Future research could see if the standard of law, whether civil or common, has an influence on compliance or results in different subgroup effects for the treatments. Future research could also consider whether there is a price premium associated with violating international incorporation standards and whether the treatments cause change to the cost of incorporation.

Although email is the standard mode of communication for this type of transaction, phone or inperson contact occurs to a lesser extent. Inferences from our approach, while capturing the dominant mode of communication, should not be made for non-email correspondence. 
Finally, what became of Vadim Mikerin? He was arrested on October 29, 2014 and was charged with soliciting bribes from lobbyists. He agreed to plead guilty to 20 charges of money laundering and bribery. These bribes and other payments, estimated to be worth $\$ 1.7$ million, were allegedly funneled through shell corporations; shell corporations that could have been set up anonymously in as few as four attempts.

\section{ACKNOWLEDGEMENTS}

The authors would like to thank Brian Silverman, Steve Tallman, Douglas Cumming, and three anonymous reviewers for their insightful comments. An earlier version of this article was presented at the Journal of International Business Studies' Paper Development Conference in London, UK (February 2016).

\section{NOTES}

${ }^{1}$ If the latter purposes are intended, anonymity and lack of transparency is desired and generally necessary to succeed. Here is where the challenge for national and international policymakers comes into play. To highlight this challenge, a group of United States Senators issued a report in 2013 on ways to stop the laundering of "blood money" from drug traffickers (United States Senate Caucus on International Narcotics Control, 2013). One of the key recommendations was to make it more difficult for criminal groups to set up and use shell corporations to launder their money in the US and throughout the global financial system. The report concludes that "it is far too easy for US corporations to have "hidden owners'" (p. 24) and notes concerns that an anonymous corporation can be set up using less information than is required to open a bank account or get a driver's license. National governments want the domestic corporate entities that have been granted legal status, rights and privileges to follow clear rules in their creation and subsequent behavior. They should be ongoing concerns with real business activities and there should also be a clear and certified knowledge of who created the entity, who the current corporate officers are, and how to contact them. Laws are enacted, and hopefully enforced, to ensure these things are accomplished for the establishment and monitoring of corporations. At the international level, standards have been created so that general consistency across country law and practice is encouraged and maintained. This allows for greater reliability within and across countries and can help address the added concerns and loss of control that may come about when dealing with cross border activities, particularly illicit ones.

${ }^{2}$ In April 2016, a leak of 11.5 million documents regarding over 200,000 offshore accounts from the Panamanian corporate service provider and law firm Mossack Fonseca revealed the widespread use of shell companies for tax avoidance, evasion of international sanctions, money laundering, and fraud. Several heads of state and their associates, as well as wealthy individuals were implicated in the documents. While many were not actually engaged in illegal activities, their use of shell companies to shelter or hide certain activities and funds came as an embarrassment and exposed the pervasive use of shell corporations.

${ }^{3}$ See Appendix A for definition of key terms.

${ }^{4}$ Private shell companies represent the vast majority of shell companies. To highlight this point, there are nearly 6000 companies collectively listed on the NYSE and NASDAQ stock exchanges, but more than 800,000 companies incorporated in the British Virgin Islands alone. Firms that list publicly have to meet exacting disclosure and reporting requirement. Private shell companies, the target of recent global regulatory initiatives and the focus of our article, are not. Fortune 500 companies and their smaller counterparts are engaged in producing substantive goods and services, whereas the large majority of shell companies do not, hence the "shell" moniker.

${ }^{5}$ The FATF standards were slightly modified in February 2012 and the various recommendations renumbered. The substance of both these international standards and the domestic laws of key jurisdictions remained constant across the period of the audit study, MERS, and field experiment. Post-2012, Recommendations 5, 12, and 33 became 10, 22 and 24, respectively.

${ }^{6}$ For developing countries, the significant decrease in refusal rates for the norms condition survived the Benjamini-Hochberg correction but not the Bonferroni adjustment, as did the increase in no-reply rates in the norms condition. The increase in non-response to the FATF condition in developing countries proved robust to both multiple-testing corrections. 


\section{REFERENCES}

Abbott, K. W., Keohane, R. O., Moravcsik, A., Slaughter, A., \& Snidal, D. (2000). The concept of legalization. International Organization, 54(3): 401-419.

Allred, B. B., \& Park, W. G. 2007. Patent rights and innovative activity: Evidence from national and firm-level data. Journal of International Business Studies, 38: 878-900.

Arend, A. C. 1997. Do legal rules matter? International law and international politics. Virginia Journal of International Law, 38: 107-154.

Bandiera, O., Barankay, I., \& Rasul, I. 2011. Field experiments with firms. Journal of Economic Perspectives, 25(3): 63-82.

Banerjee, A. V., \& Duflo, E. 2009. The experimental approach to development economics. Annual Review of Economics, 1: 151-178.

Barney, J. B. 1991. Firm resources and sustained competitive advantage. Journal of Management, 17(1): 99-121.

Benjamini, Y., \& Hochberg, Y. 1995. Controlling the false discovery rate: A practical and powerful approach to multiple testing. Journal of the Royal Statistical Society, 57(1): 289-300.

Bertrand, M. \& Mullainathan, S. 2004. Are Emily and Greg more employable than Lakisha and Jamal? A field experiment on labor market discrimination. The American Economic Review, 94(4): 991-1013.

Birkinshaw, J., Bresman, H., \& Nobel, R. 2010. Knowledge transfer in international acquisitions: a retrospective. Journal of International Business Studies, 41: 21-26.

Buckley, P., \& Casson, M. 1976. The future of the multinational enterprise. London: Palgrave Macmillan.

Butler, D. M., \& Broockman, D. E. 2011. Do politicians racially discriminate against constituents? A field experiment on state legislators. American Journal of Political Science, 55(3): 463-477.

Cantwell, J., Dunning, J. H., \& Lundan, S. M. 2010. An evolutionary approach to understanding international business activity: The co-evolution of MNEs and the institutional environment. Journal of International Business Studies, 41: 567-586.

Chatterji, A. K., Findley, M., Jensen, N. M., Meier, S., \& Nielson, D. 2016. Field experiments in strategy research. Strategic Management Journal, 37(1): 116-132.

Chayes, A., \& Chayes, A. H. 1996. The new sovereignty: Compliance with international regulatory arrangements. Cambridge, MA: Harvard University Press.

Checkel, J. T. 2001. Why comply? Social learning and European identity change. International Organization, 55(3): 553-588.

Chilton, A., \& Tingley, D. 2013. Why the study of international law needs experiments. Columbia Journal of Transnational Law, 52: 173-237.

Coffee, J. C., Jr. 2001. Do norms matter? A cross-country evaluation. University of Pennsylvania Law Review, 149(6): 2151-2177.

Demirguc-Kunt, A., Love, I., \& Maksimovic, V. 2006. Business environment and the incorporation decision. Journal of Banking \& Finance, 30(11): 2967-2993.

Djelic, M., \& Quack, S. 2003. Globalization and institutions: Redefining the rules of the economic game. Northampton, MA: Edward Elgar.

Drezner, D. W. 2007. All politics in global: Explaining international regulatory regimes. Princeton, NJ: Princeton University Press.

Duflo, E., Glennerster, R., \& Kremer, M. 2008. Using randomization in development economics research: A toolkit. In T. P. Schultz \& J. Strauss (Eds.), Handbook of Development Economics (Vol. 4, pp. 3895-3962). Amsterdam: Elsevier.

Dunn, O. J. 1961. Multiple comparisons among means. Journal of the American Statistical Association, 56(293): 52-64.

FATF. 2013. International standards on combating money laundering and the financing of terrorism \& proliferation. www.fatf-gafi.org/media/fatf/documents/recommendations/ pdfs/FATF_Recommendations.pdf, accessed 29 October 2016.

FATF. 2016. www.fatf-gafi.org/pages/aboutus/, accessed 16 September 2016.
Findley, M. G., Nielson, D. L., \& Sharman, J. C. 2014. Global shell games: Experiments in transnational relations, crime, and terrorism (Vol. 128). Cambridge: Cambridge University Press.

Findley, M. G., Nielson, D. L., \& Sharman, J. C. 2015. Causes of non-compliance with international law: A field experiment of anonymous incorporation. American Journal of Political Science, 59(1): 146-161.

Galang, R. M. N. 2012. Government efficiency and international technology adoption: The spread of electronic ticketing among airlines. Journal of International Business Studies, 43: 631-654.

Gerber, A. S., \& Green, D. P. 2012. Field experiments: Design, analysis and interpretation. New York: W.W. Norton.

Globerman, S., \& Shapiro, D. 2003. Governance infrastructure and US foreign direct investment. Journal of International Business Studies, 34: 19-39.

Goldsmith, J. L., \& Posner, E. A. 2005. The limits of international law (Vol. 199). Oxford: Oxford University Press.

Goldstein, J., Kahler, M., Keohane, R. O., \& Slaughter, A. 2000. Introduction: Legalization and world politics. International Organization, 54(3): 385-399.

Granovetter, M. 1985. Economic action and social structure: The problems of embeddedness. American Journal of Sociology, 91(3): 481-510.

Harrison, G. W., \& List, J. A. 2004. Field experiments. Journal of Economics Literature, 42(4): 1009-1055.

Hiller, D., Pindado, J., de Queiroz, V., \& de la Torre, C. 2011. The impact of country-level corporate governance on research and development. Journal of International Business Studies, 42: 76-98.

Hoskisson, R. E., Eden, L., Lau, C. M., \& Wright, M. 2000. Strategy in emerging economies. Academy of Management Journal, 43(3): 249-267.

Hyde, S. D. 2007. The observer effect in international politics: Evidence from a natural experiment. World Politics, 60(1): 37-63.

Ingram, P., \& Silverman, B. 2002. Introduction. In P. Ingram \& $\mathrm{B}$. Silverman (Eds.), The new institutionalism in strategic management (pp. 1-30). Amsterdam: Elsevier.

Kostova, T., Roth, K., \& Dacin, M. T. 2008. Institutional theory in the study of multinational corporations: A critique and new directions. Academy of Management Review, 33(4): 994-1006.

Leung, K., Bhagat, R. S., Buchan, N. R., Erez, M., \& Gibson, C. B. 2005. Culture and international business: Recent advances and their implications for future research. Journal of International Business Studies, 36: 357-378.

Leung, K., \& Morris, M. W. 2015. Values, schemas, and norms in the culture-behavior nexus: As situated dynamics framework. Journal of International Business Studies, 46: 1028-1050.

Levitt, S. D., \& List, J. A. 2009. Field experiments in economics: The past, the present, and the future. European Economic Review, 53(1): 1-18.

March, J. G., \& Olsen, J. P. 1998. The institutional dynamics of international political order. International Organization, 52(4): 943-969.

Meyer, K. E., Estrin, S., Bhaumik, S., \& Peng, M. W. 2009. Institutions, resources, and entry strategies in emerging economies. Strategic Management Journal, 30(1): 61-80.

Meyer, K. E., \& Peng, M. E. 2005. Probing theoretically into Central and Eastern Europe: Transactions, resources, and institutions. Journal of International Business Studies, 36: 600-621.

Meyer, K. E., \& Sinani, E. 2009. When and where does foreign direct investment generate positive spillovers? A meta-analysis. Journal of International Business Studies, 40(7): 1075-1094.

Miller, K. 1992. A framework for integrated risk management in international business. Journal of International Business Studies, 23: 311-331.

North, D. C. 1990. Institutions, institutional change and economic performance. Cambridge: Cambridge University Press. 
OECD. 2009. Countering Offshore Tax Evasion. www.oecd.org/ ctp/harmful/42469606.pdf, accessed 29 October 2016.

Peng, M. W., Wang, D. Y. L., \& Jiang, Y. 2008. An institutionbased view of international business strategy: A focus on emerging economies. Journal of International Business Studies, 39: 920-936.

Porter, M. E. 1980. Competitive strategy. New York: Free Press.

Redding, G. 2005. The thick description and comparison of societal systems of capitalism. Journal of International Business Studies, 36: 123-155.

Schectman, J. 2015. Russian uranium sales to US probed. Wall Street Journal, May 1, B1.

Scott, W. R. 1995. Institutions and organizations. Thousand Oaks, CA: Sage.

Shadish, W., \& Cook, T. 2009. The renaissance of field experimentation in evaluating interventions. Annual Review of Psychology, 60: 607-629.

Sharman, J. C. 2010. Shopping for anonymous shell companies: An audit study of financial anonymity and crime. Journal of Economic Perspectives, 24: 127-140.

Sharman, J. C. 2011. Testing the global financial transparency regime. International Studies Quarterly, 54: 981-1001.

Singh, J., Lentz, P., \& Nijssen, E. 2011. First- and second-order effects of consumers' institutional logics on firm-consumer relationships: A cross-market comparative analysis. Journal of International Business Studies, 42: 307-333.

Stephan, U., \& Uhlaner, L. M. 2010. Performance-based vs socially supportive culture: A cross-national study of descriptive norms and entrepreneurship. Journal of International Business Studies, 41(8): 1347-1364.
Sugathan, A., \& George, R. 2015. The influence of governance infrastructure and corporate governance on profit sharing. Journal of International Business Studies, 46: 886-916.

Teegen, H., Doh, J., \& Vachani, S. 2004. The importance of nongovernmental organizations (NGOs) in global governance and value creation: An international business research agenda. Journal of International Business Studies, 35: 463-483.

Thompson, A. G. 1996. Compliance with agreements in crosscultural transactions: Some analytical issues. Journal of International Business Studies, 27: 375-390.

United States. 1978. The Belmont Report: Ethical principles and guidelines for the protection of human subjects of research. Bethesda, MD: The Commission.

United States Senate Caucus on International Narcotics Control. 2013. The buck stops here: Improving US anti-money laundering practices.

Wang, C., Hong, J., Kafouros, M., \& Wright, M. 2012. Exploring the role of government involvement in outward FDI from emerging economies. Journal of International Business Studies, 43(7): 655-676.

Wernerfelt, B. 1984. A resource-based view of the firm. Strategic Management Journal, 5(1): 171-180.

Wood, S., Abbott, K. W., Black, J., Eberlein, B., \& Meidinger, E. 2015. The interactive dynamics of transnational business governance: A challenge for transnational legal theory. Transnational Legal Theory, 6: 333-369.

Wright, M., Filatotchev, I., Hoskisson, R. E., \& Peng, M. W. 2005. Strategy research in emerging economies: Challenging the conventional wisdom. Journal of Management Studies, 42(1): 1-33.

\section{APPENDIX A: DEFINITION OF KEY TERMS}

Anonymous shell corporation

A shell corporation for which the beneficial (real) owner has been been disguised, generally in order to operate without the scrutiny of law enforcement and public. The term shell corporation and shell company is used interchangeably in the manuscript

Compliant

Corporate service provider

(CSP)

Developing countries

Field experiment

Financial action task force (FATF)

Logic of consequences

Logic of appropriateness

Mutual evaluation reports (MERs)

Managerial School of

International Law

No response

Non-compliant

Norstralian countries
CSPs were deemed compliant if they required photo identification that was notarized/certified to complete the incorporation

A firm or sole proprietor that can incorporate a company on behalf of its founding members and can also act as the resident agent for the company

A country in which the majority lives on far less money - with far fewer basic public services - than the population in highly industrialized countries

A scientific methodology that experimentally examines an intervention in naturally occurring environments (real world), rather than in the laboratory

An international organization created by the world's leading economic powers to counter money laundering, was created to promote and enforce corporate transparency standards worldwide Adherence to laws and standards occurs only to avoid penalties or to achieve some benefit (March \& Olsen, 1998)

Adherence to international law is a function of and response to accepted norms (March \& Olsen, 1998)

Assessments conducted by FATF to determine whether a country is compliant (C), largely compliant (LC), partially compliant (PC), and non-compliant (NC) with each of the 40 Recommendations Most countries follow most international rules most of the time (Chayes \& Chayes, 1996)

Firms from which we did not receive a reply were coded as no response CSPs were deemed non-compliant if they did not request any photo identity to complete the incorporation

Wealthy, low-corruption OECD countries (Norway, Finland, Sweden, Denmark, the Netherlands, Austria, New Zealand, or Australia). The Norstralian countries are among the least corrupt countries ranked on the Transparency International Corruption Perceptions Index (CPI) and are where the consultants in our study claimed to be from 
OECD countries A collection of 34 countries with the world's most advanced and developed economies that have committed to enact and enforce its standards for transparency in corporate governance. These countries adhere to the rule of law and have relatively well-funded, capable judicial, regulatory and law enforcement

Partially CSPs were deemed partially compliant if they requested photo identification to complete the incorporation, but did compliant not ask the it be notorized/certified

Refusal of Incorporation firms that did respond, but refused to offer their services were deemed Refusal of Service

Service

Tax Havens Countries identified by the OECD as those that host companies not engaged in substantive business activities, that apply low or zero tax rates, do not exchange tax information with other governments, and have little transparency

APPENDIX B: SUMMARY OF FAFT MUTUAL EVALUATION REPORTS AUDITS

\begin{tabular}{|c|c|c|c|c|c|c|}
\hline & \multicolumn{2}{|c|}{ Recommendation 10} & \multicolumn{2}{|c|}{ Recommendation 22} & \multicolumn{2}{|c|}{ Recommendation 24} \\
\hline & Frequency & Percentage & Frequency & Percentage & Frequency & Percentage \\
\hline Non-compliant & 72 & $46.2 \%$ & 114 & $70.4 \%$ & 49 & $30.6 \%$ \\
\hline Partially compliant & 71 & $45.5 \%$ & 44 & $27.2 \%$ & 85 & $53.1 \%$ \\
\hline Largely compliant & 13 & $8.3 \%$ & 4 & $2.5 \%$ & 20 & $12.5 \%$ \\
\hline Compliant & 0 & $0.0 \%$ & 0 & $0.0 \%$ & 6 & $3.8 \%$ \\
\hline Total & 156 & $100.0 \%$ & 162 & $100.0 \%$ & 160 & $100.0 \%$ \\
\hline
\end{tabular}

Appendix B provides a summary of the FATF MERs for countries throughout the world, focusing on the three key FATF recommendations. They provide four outcome categories, and the table shows the distribution of compliance levels across the countries and recommendations. Only a small percentage of countries were Largely Compliant and only Recommendation 33 had any countries identified as fully Compliant. The vast majority of country audits indicated either NonCompliance or Partial Compliance with the transparency standards.

Appendix $\mathrm{C}$ shows the results of regression analysis considering whether national level compliance with each of the recommendations predicts firm level compliance. Each of the
"Recommendation" variables is an ordered scale ranging from non-compliance to full compliance ( 1 = non-compliant, $\quad 2$ = partially compliant, $3=$ largely compliant, and $4=$ compliant) for national level assessments and predict percent firm-level compliance. The model is estimated using ordinary least squares regression analysis. National compliance does not predict firm-level compliance for FATF Recommendations 5 and 12 and predicts virtually none of the variance. For Recommendation 33, national compliance is a significant predictor (at the $\mathrm{p}<0.05$ level), but less than $4 \%$ of the variance is explained, offering weak substantive support for the proposition that statutory law drives firm-level behavior across the full sample.

\section{APPENDIX C: REGRESSION ANALYSIS}

\begin{tabular}{lccc}
\hline & Model 1 & Model 2 & Model 3 \\
\hline Constant & $0.579(0.070)$ & $0.495(0.066)$ & $0.385(0.66)$ \\
Recommendation 10 & $-0.039(0.039)$ & $0.014(0.046)$ & $0.063(0.030)$ \\
Recommendation 22 & & & 0.0399 \\
Recommendation 24 & 0.0010 & 0.0009 & 0.031 \\
$\mathrm{R}^{2}$ & -0.0001 & -0.0087 & $2.060^{*}$ \\
Adj. $\mathrm{R}^{2}$ & 0.990 & 0.090 & 104 \\
$\mathrm{~F}$ & 102 & 106 & 104 \\
$\mathrm{~N}$ & & & \\
\hline
\end{tabular}

$+p<0.10 ;{ }^{*} p<0.05 ;{ }^{* *} p<0.01 ;{ }^{* * *} p<0.001$ 


\section{APPENDIX D: EXAMPLE EMAILS USED IN STUDY}

\section{Control (Placebo) Email}

\section{Dear [name/company]}

I am contacting you as I would like to form an international corporation for my consulting firm. I am a resident of [Norstralia] and have been doing some international consulting for various companies. We are now growing to a size that make incorporation seem like a wise option. A lot of our newer business is in your region.

My two associates and I are accustomed to paying [Norstralia] income taxes, but the rising tax rates make incorporation in another country a more economical alternative. Also, our contracts grow larger and more complicated, so reducing personal liability through incorporation seems more attractive.

As I am sure you understand, business confidentiality is very important to me and my associates. We desire to incorporation as confidentially as we can. Please inform us what documentation and paperwork is required and how much these services will cost?

I would like to start the process of incorporation as soon as possible. Also, how much can we expect your fees to be?

Due to numerous professional commitments, I would prefer to communicate through email. I hope to hear from your soon.

Thank you very much, [alias]

\section{Treatment Email: International Standard}

\section{Dear [name/company]}

I am contacting you regarding a business I am trying to set up. I am a consultant and my colleagues and I are seeking to establish an international corporation. I am [Norstralia] resident, but I do business both locally and with some international clients, including some in your region. Out business has been growing substantially, and our goal is to limit tax obligations and business liability.

We would like as much business confidentiality as possible in these early stages of formation. My internet searches show that the international Financial Action Task Force requires disclosure of identifying information. But I would rather not provide any detailed personal information, if possible.
So, we would like to know what identifying documents will be required to establish this company. We would also like to know what start-up costs will be.

Due to my travel schedule, email will be the best way to reach me. I look forward to hearing from you soon.

$$
\text { Regards, [alias] }
$$

\section{Treatment Email: Consequences}

\section{Dear [name/company]}

I am seeking information on how to incorporate an international company. I hope you might be able to offer what I need.

I am a consultant, and my colleagues and I live in [Norstralia]. Much of our business originates here, where we operate, but our company also grows quickly among international clients. Many of them are in your area. So, we feel that incorporation is a necessary option of us. We hope to limit taxes obligations and business liability.

We would like to know if you feel that you will be able to service us with a corporation. What identifying documents will you request for this transaction? We would prefer to limit disclosure as much as possible.

My internet searches show that the international Financial Action Task Force sets standards for disclosure of identifying information when forming a company. I also understand that legal penalties may follow violation of these standards. But I would like to avoid providing any detailed personal information if possible. If you could answer these questions and also let us know about your prices, we very much appreciate it.

Thank you for the time to address our query. Business obligations make communication difficult, so we would prefer to correspond with email.

Until we speak again, [alias]

\section{Treatment Email: Appropriateness}

\section{Dear [name/company]}

I am a resident of [Norstralia] and would like to inquire about your process to form international corporations. With several associates, I operate a consulting firm in [Norstralia]. We deal with a growing number of international clients, many that come from your area, and would like to pursue incorporation option for liability and taxes purposes. 
We are particularly concerned with keeping business interactions private; thus, we are eager to limit information disclosure as much as possible. My internet searches show that the international Financial Action Task Force sets standards for disclosure of identifying information when forming a company and most countries have signed on to these standards. As reputable businessmen, I am sure we both want to do the right thing by the international rules. But I would like to avoid providing any detailed personal information if possible.

Can you please inform me what your start-up costs are and what kind of identification or documents we will need to provide? We are all fairly burdened with commitments, so email communication is preferable.

Thank you in advance, [alias]

\section{ABOUT THE AUTHORS}

Brent B Allred is Professor of Strategy and International Business in The College of William and Mary's Raymond A. Mason School of Business. He earned his $\mathrm{PhD}$ from The Pennsylvania State University. His current research interests explore global corruption and governance, technology sourcing, and patent rights. His papers have been published in journals such as the Journal of International Business Studies, Journal of Product Innovation Management, Management International Review, Journal of International Management, and Academy of Management Executive.

Michael G Findley is Associate Professor of Government in the University of Texas at Austin Department of Government. He earned his PhD from The University of Illinois at Urbana-Champaign. His current research interests include political violence, international development, and international law. His work has been published in journals such as Strategic Management Journal, International Organization, World Development, Public Choice, Complexity, American Journal of Political Science, Journal of Politics, University of Minnesota Law Review, and Cambridge University Press.

Daniel Nielson is Professor and Associate Chair of Political Science at Brigham Young University. His work studies international development through field experiments, with a focus on corruption and governance. He is co-author of Global Shell Games: Experiments in Transnational Relations, Crime, and Terrorism (Cambridge, 2014) and co-editor of Delegation and Agency in International Organizations (Cambridge, 2006). Among other journals, his articles have appeared in the Strategic Management Journal, American Journal of Political Science, International Organization, University of Pennsylvania Law Review, International Studies Quarterly, and World Development.

J C Sharman is the Sir Patrick Sheehy Chair of International Relations in the Department of Politics and International Studies at the University of Cambridge. Sharman's research is focused on corruption, money laundering and tax havens, as well as the international relations of the early modern world. His latest books are International Order in Diversity: War, Trade and Rule in the Indian Ocean (Cambridge University Press, 2015 with Andrew Phillips) and The Despot's Guide to Wealth Management (Cornell University Press, 2017). 